\title{
Analyse de la prévoyance
}

\section{L'incapacité de gain peut tous nous concerner}

\section{Les assurances légales couvrent vos besoins d'une manière insuffisante}

La Suisse dispose d'un des meilleurs systèmes d'assurances sociales du monde. Cependant les prestations sociales légales du $1^{\text {er }}$ et $2^{\text {ème }}$ pilier ne suffisent pas à assurer la continuité du train de vie désiré.

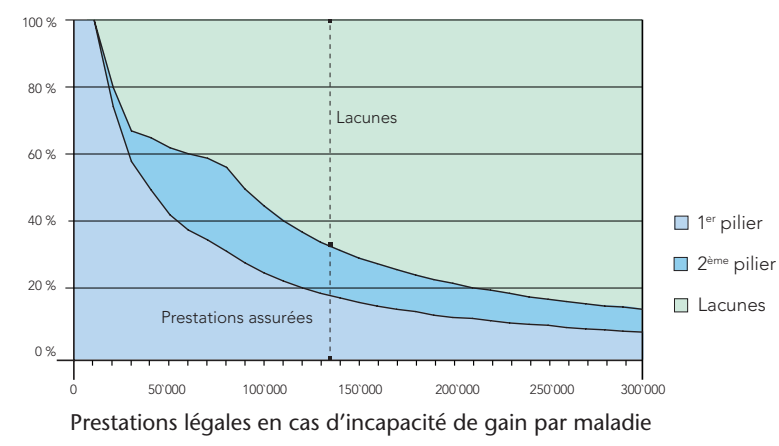

\section{Profiter de notre offre}

Vos préoccupations de prévoyance sont au centre de nos activités. Notre société vous garantit un conseil personnalisé par une équipe de spécialistes avec une longue expérience dans les domaines des assurances et des produits bancaires. Grâce à notre indépendance nous pouvons vous offrir les meilleurs produits les mieux adaptés à vos besoins.

\section{Nos spécialistes analysent sérieusement votre situation de prévoyance actuelle}

Par une analyse personnelle de prévoyance toutes les lacunes de couverture et les doublons sont découverts. Nos spécialistes vous proposent des solutions adéquates. Le premier rendez-vous est gratuit.

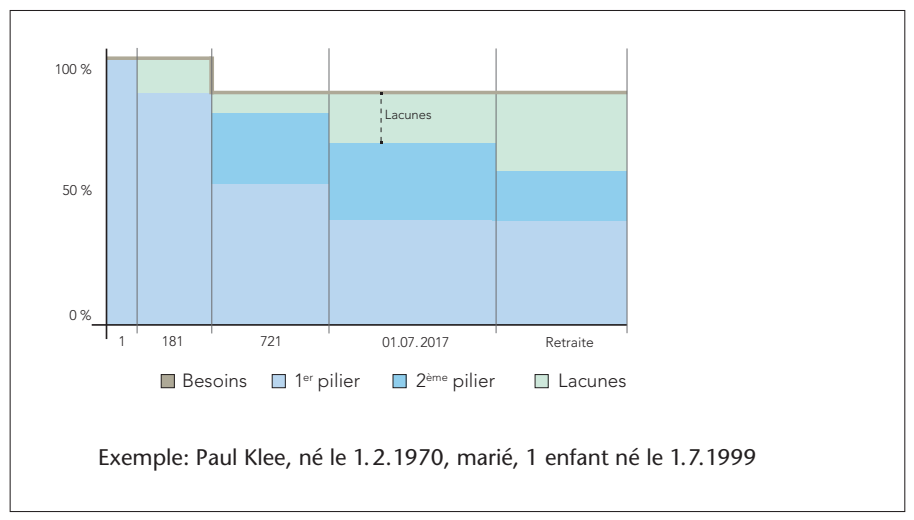
$8<$

\section{Talon réponse}

Prénom / Nom

Adresse

NPA / Lieu

Date de naissance

Téléphone privé/cabinet

Atteignable le plus facilement (heure)

O Je désire un conseil personnalisé.

Prière de me téléphoner.

Je suis intéressé à:

$\begin{array}{ll}\text { Caisse-maladie } & \bigcirc \text { Caisse de pension LPP } \\ \text { 3e }^{\text {pilier a }} & \bigcirc \text { Protection juridique } \\ \text { Planification financière } & \bigcirc \text { Responsabilité civile profess. } \\ & \end{array}$

